Article

\title{
European Digital Elevation Model Validation against Extensive Global Navigation Satellite Systems Data and Comparison with SRTM DEM and ASTER GDEM in Central Macedonia (Greece)
}

\author{
Antonios Mouratidis ${ }^{1, *(1)}$ and Dimitrios Ampatzidis ${ }^{2}(\mathbb{D}$ \\ 1 Department of Physical and Environmental Geography, Aristotle University of Thessaloniki, \\ 54124 Thessaloniki, Greece \\ 2 Federal Agency for Cartography and Geodesy, Richard-Strauss-Allee 11, \\ 60598 Frankfurt am Main, Germany; Dimitrios.Ampatzidis@bkg.bund.de \\ * Correspondence: amourati@geo.auth.gr
}

Received: 11 January 2019; Accepted: 25 February 2019; Published: 28 February 2019

\begin{abstract}
Digital elevation models (DEMs) are a widely used form of topographic information, with some of the most popular being the Shuttle Radar Topography Mission (SRTM) DEM and the Advanced Spaceborne Thermal Emission and Reflection Radiometer Global Digital Elevation Model (ASTER GDEM). These two sources of topographical information are the main constituents of the European Union Digital Elevation Model (EU-DEM), which is a relatively new dataset of the EU's Copernicus Land Monitoring Service. In this context, the purpose of this study was to validate EU-DEM for its vertical accuracy and to compare it with SRTM DEM and ASTER GDEM data. This was achieved in a Geographic Information System (GIS) environment, using extensive-in the order of tens of thousands of points-geodetic Global Navigation Satellite System (GNSS) measurements and appropriate pre-processing steps. The absolute elevation errors results had a Root Mean Square Error (RMSE) of $2.7 \mathrm{~m}$ at a $90 \%$ confidence level and characterize the performance of EU-DEM from local to regional scale, generally confirming that it is an enhanced source of elevation information when compared with its predecessors.
\end{abstract}

Keywords: EU-DEM; SRTM; ASTER GDEM; DEM; DTM; digital elevation model; Copernicus; GNSS; GIS; validation

\section{Introduction}

Digital elevation models (DEMs) are the most popular form of topographic data. The positive impact of (almost) global and publicly available DEMs from space-based measurements, such as the Shuttle Radar Topography Mission (SRTM) DEM data [1] and the Advanced Spaceborne Thermal Emission and Reflection Radiometer Global Digital Elevation Model (ASTER GDEM) [2-4], has been verified by the plethora of their applications. SRTM DEM has been described as the most dramatic advance in cartography since Mercator [5], whereas current products, like ALOS Global Digital Surface Model "ALOS World 3D-30 m (AW3D30)" [6] or WorldDEM ${ }^{\mathrm{TM}}$ [7], and near-future mission concepts such as the Lidar Surface Topography (LIST) [8] emphasize the quest for increasingly accurate descriptions of the global topography and underline the topography's time dependence, turning its measurement into a continuous task [5]. 
In this context, the European Union Digital Elevation Model (EU-DEM) is a new hybrid product principally based on SRTM DEM and ASTER GDEM data, and on publically available Russian topographic maps for regions north of $60^{\circ} \mathrm{N}$. More EU-DEM is a Digital Surface Model (DSM) over Europe from the Global Monitoring for Environment and Security (GMES) Reference Data Access (RDA) project-a realization of the Copernicus (former GMES) program, managed by the European Commission/DG Enterprise and Industry.

The first version (v1) of EU-DEM was released in October 2013. For the first year, the data were provided without formal validation [9]. Subsequently, an independent statistical validation, scheduled as part of the GMES Initial Operations (GIO) land monitoring service activities, was officially released in August 2014 [10]. In April 2016, an updated version (v1.1) of EU-DEM was released as an upgrade that enhances the correction of geo-positioning issues, reducing the number of artefacts, improving the vertical accuracy of EU-DEM, and ensuring consistency with other relevant public EU geospatial data [11].

DEM vertical accuracy is influenced by several factors such as slope, land cover, and geolocation (horizontal) error, as well as other systematic biases due to the original DEM data collection (e.g., satellite imaging geometry) and/or production method. In addition, irrespective of the vertical accuracy, a qualitative assessment of DEMs may be crucial for specific disciplines such as geomorphology [3,12-17].

Validation of DEMs produced from Earth observation data, such as SRTM DEM, ASTER GDEM, and other less extensive DEMs, is commonly performed using datasets of higher accuracy, typically of at least one order of magnitude. The sources of these datasets have been higher resolution DEMs [15,16], medium to large-scale topographic maps [17], altimetric data [18,19], surveying or Global Positioning System (GPS) measurements [20-25], as well as global [15] or regional [26] kinematic GPS (KGPS) campaigns.

The most extensive global ground-truth effort was completed for the validation of SRTM data by collecting a globally distributed set of ground control points (GCPs) using KGPS transects. The KGPS data were collected by vehicles carrying GPS receivers. The total data collection yielded nearly 9.4 million samples covering six continents with a general accuracy of about $50 \mathrm{~cm}$. In the end, more than $2,000,000$ of the aforementioned GCPs were included in this validation endeavor $[15,27]$. The most detailed study for the validation of DEMs for a large area was performed on a local to regional level with over 60,000 KGPs data points [26], with the density of the KGPs data collected (about 8.6 points $/ \mathrm{km}^{2}$ ) being more than 100 times larger with respect to the data density used for the global assessment of SRTM (about 0.06 points $/ \mathrm{km}^{2}$ ).

The vertical accuracy specifications of the SRTM DEM at $90 \%$ confidence have a Root Mean Square Error (RMSE) of $9.73 \mathrm{~m}$ for absolute elevations and a RMSE of $6 \mathrm{~m}$ for relative elevations on a local 50-100 km scale [1,28-31]. SRTM DEM data have been validated by many other authors, with most of them concluding that the vertical accuracy is significantly better than the nominal accuracy. The official global vertical accuracy of ASTER GDEM version 2 (v2) is characterized by an RMSE of $17 \mathrm{~m}$ at 95\% confidence [4,16,32], as opposed to the officially reported vertical accuracy of $20 \mathrm{~m}$ RMSE (95\%) for ASTER GDEM v1 [3]. According to Varga and Bašić [33], many other studies have investigated ASTER GDEM, reporting a RMSE range of estimated vertical accuracy between $6 \mathrm{~m}$ and $30 \mathrm{~m}$. For the same area as per this study, SRTM DEM and ASTER GDEM v1 data have both been previously validated for their vertical accuracy [26,34], with results yielding a RMSE of $6.4 \mathrm{~m}$ and $12.5 \mathrm{~m}$, respectively.

According to the independent statistical validation of EU-DEM v1 [10], the overall EU-DEM v1 vertical accuracy was assessed to have an RMSE of $2.90 \mathrm{~m}$ ( $95 \%$ confidence). This general accuracy, however, masks a distinct difference between latitudes south and north of $60^{\circ} \mathrm{N}$. The calculation of the vertical accuracy for these two regions separately reveals an overall vertical RMSE accuracy of $2.23 \mathrm{~m}$ for the region south of $60^{\circ} \mathrm{N}$ and an RMSE of $5.19 \mathrm{~m}$ for the region north of $60^{\circ} \mathrm{N}$ at $95 \%$ confidence, whereas, specifically for Greece, the vertical RMSE is in the order of $2 \mathrm{~m}(95 \%)$. This lower accuracy in the northern latitudes is attributed to the lack of SRTM data north of $60^{\circ} \mathrm{N}$ and hence to the reliance 
on ASTER GDEM data alone or the combination of ASTER GDEM and Russian topographic maps [10]. The RMSE of the nominal vertical accuracy of the upgraded version (EU-DEM v1.1) has been estimated to be in the order of $7 \mathrm{~m}[35,36]$. The quality of the data has been verified by several quality control process, including a statistical comparison and visual checks [36].

A local scale (area of about $25 \times 15 \mathrm{~km}$ ) and relatively small elevation range (139-682 m) of EU-DEM v1 was more recently reported in Hungary [37]. EU-DEM v1 was compared against ASTER GDEM, SRTM DEM, and contour-based DEMs from 1:10,000 scale topographic maps. The latter DEM was interpolated with a 10-m cell size and then downsampled to $30 \mathrm{~m}$ to represent the ground truth values, ultimately estimating the RMSE of the vertical accuracy of EU-DEM to be between $6.0 \mathrm{~m}$ and $7.8 \mathrm{~m}$.

Based on this background, the objective of this study was to validate the vertical accuracy of EU-DEM (both v1 and v1.1) on a local to regional scale against primary elevation data measured in the field with high reliability, as well as to compare it with SRTM DEM and ASTER GDEM data. This was essentially achieved in a Geographic Information System (GIS) environment using extensive-in the order of tens of thousands of points-geodetic Global Navigation Satellite Systems (GNSS) measurements preceded by appropriate pre-processing steps. The main purpose was to examine the hypothesis that EU-DEM synthesizes the advantages of its sources, i.e., is characterized by a higher vertical accuracy than SRTM DEM and ASTER GDEM.

As EU-DEM is produced through a fusion processing chain including both horizontal and vertical shifting as well as smoothing of the input layers [36], this independent study involved a blind experiment in that the exact algorithm that produced EU-DEM from SRTM DEM and ASTER GDEM data was not known a priori.

\section{Study Area}

The study area extends over an area of about $100 \times 70 \mathrm{~km}$ in Central Macedonia, Northern Greece (Figure 1a). Land cover consists mainly of agricultural areas or pastures $(\sim 60 \%)$, shrubs or low vegetation $(\sim 20 \%)$, and forests $(\sim 10 \%)$ (Figure $1 \mathrm{~b})$. Its topography varies from extensive lowlands and (locally) below Mean Sea Level (MSL) elevation areas, owing to subsidence, to hilly and mountainous regions (Figure 1c). Since 2008, the area has been serving as a test site for the GNSS-assisted validation of various DEMs derived from Earth observation data, such as the four available versions of SRTM DEM [26], the first version of ASTER GDEM (released in 2009), photogrammetrically produced DEMs from stereoscopic SPOT images, Interferometric Synthetic Aperture Radar (InSAR) DEMs from ERS tandem data, as well as DEMs originating from the digitization of topographical maps [34]. 

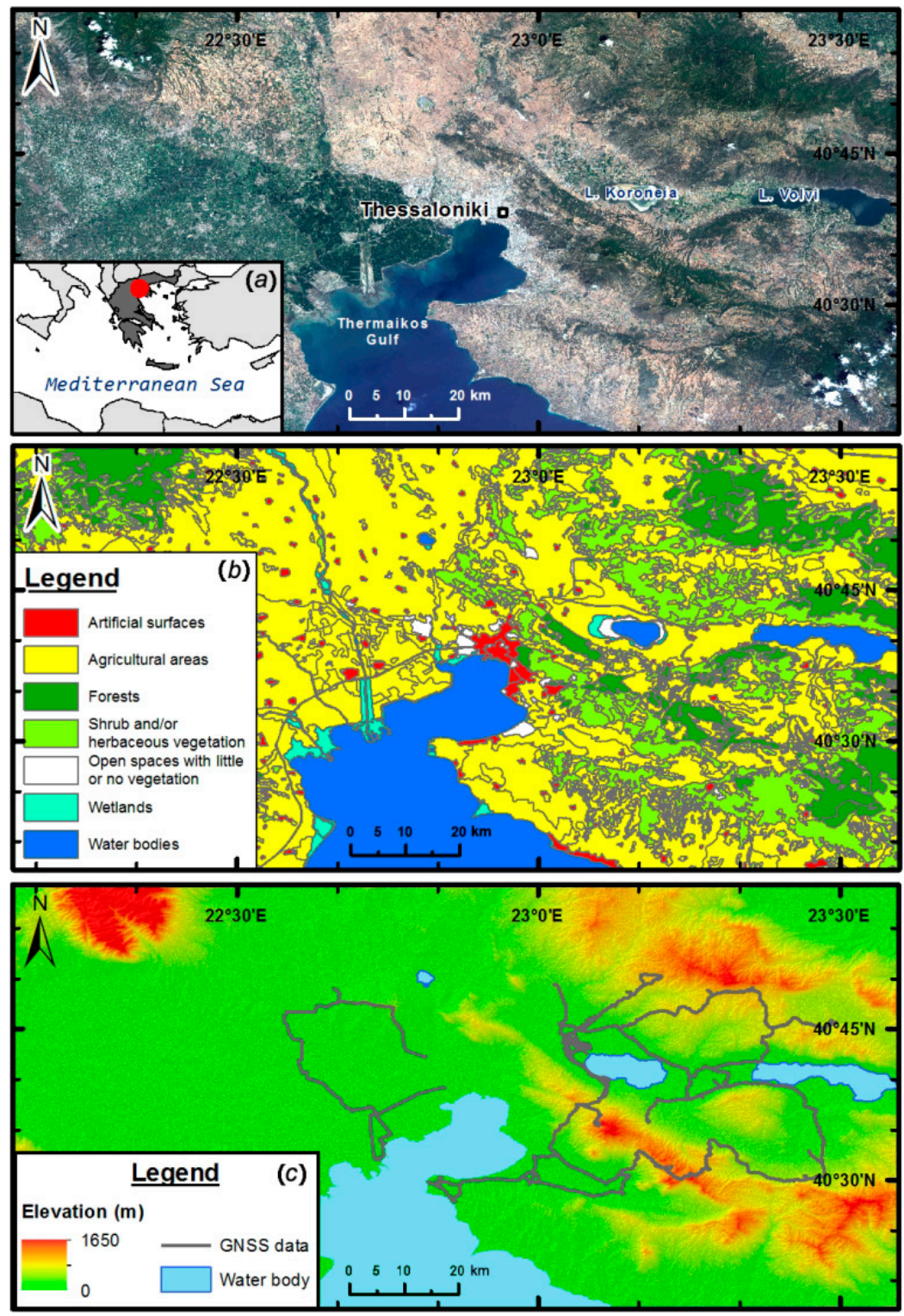

Figure 1. (a) Broad overview of the study area, as seen in a Landsat-8OLI (Operational Land Imager) true color composite image; (b) land cover of the study area according to Corine Land Cover data; and (c) topography of the study area and tracks of Global Navigation Satellite Systems (GNSS) data collected for DEM validation purposes.

\section{Materials and Methods}

\subsection{Data Used in the Evaluation}

\subsubsection{Digital Elevation Models}

The DEMs simultaneously evaluated in this study included:

(1) EU-DEM v1: The original version of EU-DEM produced by merging NASA's SRTM DEM v2 (also known as the "finished" version) with ASTER-GDEM v2 1-arcsec data to generate a 1-arcsec resolution (about $23 \times 30 \mathrm{~m}$ in the study area) DEM using a weighted averaging approach. EU-DEM is generated as a contiguous dataset divided into $1^{\circ} \times 1^{\circ}$ tiles, corresponding to the SRTM DEM naming convention. The spatial reference system of EU-DEM is geographic latitude/longitude, with horizontal datum ETRS89, ellipsoid GRS80 and vertical datum the 
European Vertical Reference System 2000 (EVRS2000), using the European Gravimetric Geoid model EGG08. The $1^{\circ} \times 1^{\circ}$ tiles are then also aggregated into $5^{\circ} \times 5^{\circ}$ tiles, which are further projected to the European Terrestrial Reference System 1989-Lambert Azimuthal Equal Area projection (ETRS89-LAEA) by the Joint Research Centre (JRC) [9].

(2) EU-DEM v1.1: A resulting dataset of the EU-DEM v1.0 upgrade, enhancing geolocation accuracy with the use of SPOT 2011 imagery, screening and removal of artefacts including the presence of blunders (i.e., negative or positive anomalies), improving the vertical accuracy using Ice, Cloud, and land Elevation Satellite (ICESat) data as reference (bias adjustment with ICESat points), as well as ensuring consistency with EU-Hydro 2015 data (river networks, coastlines, water bodies). EU-DEM v1.1 is only provided in projected coordinates (ETRS89-LAEA) in grouped tiles covering extensive regions at a $25-\mathrm{m}$ resolution [11].

(3) SRTM DEM v4: A 3-arcsecond resolution (about $69 \times 90 \mathrm{~m}$ in the study area) DEM, delivered in $5^{\circ} \times 5^{\circ}$ tiles by the Consultative Group on International Agricultural Research-Consortium for Spatial Information (CGIAR-CSI) [38]. A thorough validation of SRTM DEM for the area of interest can be found in Mouratidis et al. [26]. Note that according to Mouratidis et al. [26], for the area of interest, the CGIAR-CSI SRTM v4 is identical to SRTM v2 from NASA. The reason why $\mathrm{v} 4$ is used here is because it is provided in larger tiles than v2; thus, for a reasonable study area extent, the process of having to mosaic different SRTM DEM tiles can usually be avoided. The data are provided in the World Geodetic System of 1984 (WGS 84) latitude and longitude and orthometric height with respect to the Earth Geopotential Model of 1996 (EGM96) [39].

(4) ASTER GDEM version two (v2): This stereoscopic product is an improved version of the first release in 2009, with a resolution of 1 arcsecond (about $23 \times 30 \mathrm{~m}$ in the study area) [4]. It includes 260,000 additional scenes to improve coverage, a smaller kernel-to-yield correlation, higher spatial resolution, and improved water masking. The negative $5 \mathrm{~m}$ overall bias observed in ASTER GDEM v1 was eliminated in the newer version. ASTER GDEM v2 is distributed in $1^{\circ} \times 1^{\circ}$ tiles. The data are given in WGS 84 latitude and longitude and orthometric height with respect to the EGM96 geoid.

\subsubsection{GNSS Data}

The original reference dataset used for the validation of DEMs consists of a total of about 70,000 GNSS (GPS and GLONASS) points (Figure 1c), collected during three campaigns between 2008 and 2011. More specifically, the dataset consists of about 60,000 kinematic and static GPS observations from 2008 [26], about 10,000 kinematic and static GNSS (using GPS and GLONASS) points from Mouratidis and Albanakis [40], as well as a few additional GNSS points (again, using both GPS and GLONASS signals) collected in static mode in 2011. The kinematic data were surveyed on roads, whereas the static observations involve the various positions of the reference receivers (bases) used for the kinematic surveys.

Both static and kinematic observations were collected with dual-frequency GNSS receivers and were post-processed. The RMSE of the vertical accuracy of all data collected during the period 2008-2011 ranged between $1 \mathrm{~cm}$ and $1.5 \mathrm{~m}$ at 95\% confidence. The orthometric elevations of the data collected range from $-2 \mathrm{~m}$ to $890 \mathrm{~m}$.

The raw GNSS data are referenced to the International Terrestrial Frame of 2005 (ITRF2005) [41] and provide geometric (ellipsoidal) heights with reference to the World Geodetic System 1984 (WGS84) ellipsoid.

\subsubsection{Other Data and Software}

Additional data used for the validation of the various DEM included Corine Land Cover information of 2012 (CLC 2012) [42].

Most of the processing took place in a GIS software, namely ArcGIS ${ }^{\mathrm{TM}}$ (ESRI, Redlands, CA, USA). 


\subsection{Data Preparation}

\subsubsection{Horizontal and Vertical Datum Transformations}

As EU-DEM only concerns Europe and adjacent areas, the reference systems used for the validation procedures in this study were chosen to be those of EU-DEM, i.e., ETRS89 (horizontal) and EVRS2000 (vertical). Therefore, GNSS, SRTM DEM, and ASTER GDEM data were all initially converted to ETRS89/EVRS2000.

In order to be consistent with ETRS89/EVRS2000, the following steps were followed:

(1) WGS84 refers to the current ITRF solution with an accuracy of $10 \mathrm{~cm}$ [43]. Using the Boucher-Altamimi memo [44], the ETRS89 coordinates were calculated. For this purpose, MATLAB (MathWorks, Natick, MA, USA) scripts were developed and then tested against the officially released tools [45], with the accuracy of the transformation being better than $20 \mathrm{~cm}$.

(2) The difference in the Earth gravity field potential W0 between EGM96 [39] and EVRS2000 [45] were also considered. Practically, these two vertical datums have a shift difference $\left(\Delta W 0 / \gamma \_\right.$mean $)$of $-51 \mathrm{~cm}$, which was considered.

With respect to the calculation of orthometric elevations, although EGG08 exists for Europe, it has not been validated in Greece [46]. The vertical data for Greece are not connected to EVRS and there is no real evidence of EGG08 accuracy in Greece because data is not publically available. A satisfactory Earth Gravitational Model 2008 (EGM2008) assessment is available for Greece [47]. Thus, instead of EGG08, the EGM 2008 geoid was used for ellipsoidal to orthometric elevation transformations of GNSS data.

Concerning the GNSS point dataset, the RMSE of the accuracy of ellipsoidal height (h) determination with differential GPS (DGPS) is in the order of $0.5-1 \mathrm{~m}$ [48]. Orthometric heights $(\mathrm{H})$ are then derived from ellipsoidal heights, by subtracting the geoidal undulation (N), i.e., $\mathrm{H}=\mathrm{h}$ RMSE N [49]. Thus, for the present case study, N refers to the EGM2008 [50], from which the geoidal undulation accuracy in Greece is estimated with a standard deviation of approximately $15 \mathrm{~cm}$ [51-53]. With the above considerations and considering the error propagation, the RMSE of the overall original accuracy of the orthometric elevations for the GNSS points collected is in the order of $1 \mathrm{~m}$.

All datasets used in the validation process (apart from the CLC 2012 layer, which was already georeferenced in ETRS89-LAEA) were also projected to ETRS89-LAEA coordinates, in order to (1) evaluate the DEM vertical accuracy by deriving and considering slope information and (2) validate EU-DEM v1.1, which is only provided in projected coordinates.

\subsubsection{GNSS Data Pre-Processing}

The original 70,000 GNSS points, equivalent to a density of about 10 points $/ \mathrm{km}^{2}$ in the study area, were filtered in several steps: (1) points with vertical RMSE > $1 \mathrm{~m}$ were eliminated; (2) based on a priori knowledge of the study area, points under overpasses, bridges, etc. were eliminated; (3) points whose elevation had a standard deviation of more than $1 \mathrm{~m}$ within a 30-m distance or more than $5 \mathrm{~m}$ for 90-m distance were removed using respective thresholds [15,26]; and (4) to ensure equally distributed weight among the evaluated EU-DEM pixels and increased vertical accuracy, multiple GNSS points that fell within a single EU-DEM one arcsecond pixel (approx. $23 \mathrm{~m} \times 30 \mathrm{~m}$ at the latitude of the area of interest) were averaged.

After completing the above procedures, the final GNSS dataset for validating the available DEMs consisted of 12,943 points, each one corresponding to a discrete EU-DEM pixel. These GNSS points were then saved as a separate GIS vector layer, with the orthometric elevation value of each point registered in the layer's attribute table. 


\subsubsection{Pre-Processing of DEMs}

As a first pre-processing step, the 3 arcsecond SRTM data were resampled to a 1 arcsecond grid, using nearest neighbor interpolation to match the grids of EU-DEM and ASTER GDEM without altering the original pixel (elevation) values.

Next, the actual area of interest, corresponding to the spatial extent of GNSS points available, was defined in each dataset and the relevant subsets were created, each containing $4542 \times 2384$ pixels (approx. $100 \times 70 \mathrm{~km}$ ).

The raster DEM data were compared against vector GNSS points in a GIS environment by converting the former to vector format [23,26]. More specifically, all DEMs were converted to vector GIS layers (shapefiles), as polygons (rectangles) with same size as the former raster cells, while the elevation value of each cell was retained in the attribute table of the respective polygon. Subsequently, the vector GIS layer of the final GNSS points was overlain on each of the DEM shapefiles. Finally, the DEM elevation value at the location of each GNSS point was transferred in the attribute table of the GNSS in a separate column (one for every DEM). With this, we validated DEM elevation via GNSS elevations by comparing two columns of corresponding data values in a spreadsheet.

\section{Results}

\subsection{Direct Comparison of EU-DEM with SRTM DEM and ASTER GDEM}

Considering EU-DEM is practically a mathematical product mainly stemming from ASTER GDEM and SRTM DEM data, prior to assessing the accuracy of the individual DEMs, we acquired an overview of the differences between the three datasets. To this end, we completed a relative DEM comparison by executing the following subtractions: (EU-DEM) - SRTM DEM, (EU-DEM) -ASTER GDEM, SRTM DEM-ASTER GDEM (Figure 2). This comparison first highlighted the extensive similarity of EU-DEM with SRTM DEM for low elevation (and thus low slope) areas (depicted in yellow in Figure 2a). On the contrary, major differences were observed at higher elevations. SRTM DEM elevations are overall quite close to EU-DEM values with a SD of approx. $4.9 \mathrm{~m}$. With reference to ASTER GDEM (Figure 2b), EU-DEM presents significant discrepancies (mean of approx. $4.7 \mathrm{~m}$ and SD of $7.3 \mathrm{~m}$ ) at both low and high elevations, but the deviations over rugged terrain and steep slopes are generally smaller than those with respect to SRTM DEM. The differences between SRTM DEM and ASTER GDEM (Figure 2c) presented a mean value of $4.4 \mathrm{~m}$ and a SD of $8.3 \mathrm{~m}$. The result of this evaluation is both visually and statistically similar with the EU-DEM-ASTER GDEM comparison, verifying that EU-DEM and SRTM data values are overall not too far apart. The upgraded version of EU-DEM (EU-DEM v1.1) presented significant elevation differences from the original version, especially over hilly and mountainous areas, with an overall SD of $2.1 \mathrm{~m}$ (Figure 3).

\subsection{Absolute Elevations}

Absolute vertical accuracy was estimated for all available DEMs with reference to the 12,943 GNSS points. The computed differences were calculated following a "DEM-GNSS" subtraction approach in all three cases, i.e., ASTER GDEM-GNSS, SRTM DEM-GNSS, and (EU-DEM)-GNSS. For EU-DEM, two separate evaluations were completed: for the original EU-DEM and for the EU-DEM upgrade (v1.1).

Histograms (Figures 4 and 5) of the results show that the elevation values of EU-DEM are closer to the "real" values measured by GNSS. This was quantified in the corresponding descriptive statistics (Table 1), where mean, standard deviation, and range (min-max) of the values of EU-DEM elevation errors are considerably better than those of ASTER GDEM and SRTM DEM. Additionally, given the known non-normality of the differences (residuals) between ground data and DEMs (kurtosis and skewness), some more robust statistical measures have been included according to Höhle and Höhle [54], so that the absolute elevation validation is also based on median and Normalized Median Absolute Deviation (NMAD) values. 


\section{Legend \\ Water body \\ (EU-DEM)-SRTM DEM \\ Elevation difference (m) \\ Max: 55 \\ Min: -75}
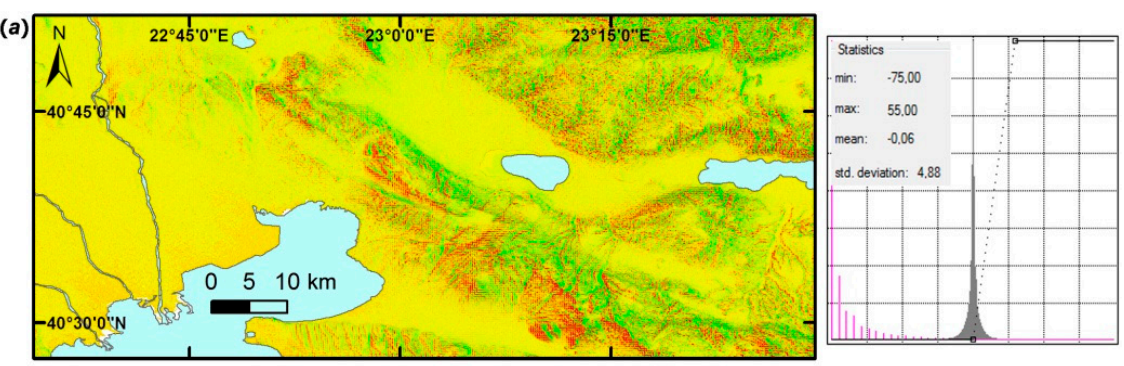

\section{Legend}

Water body

(EU-DEM)-ASTER GDEM

Elevation difference $(\mathrm{m})$

Max: 108

Min: -59
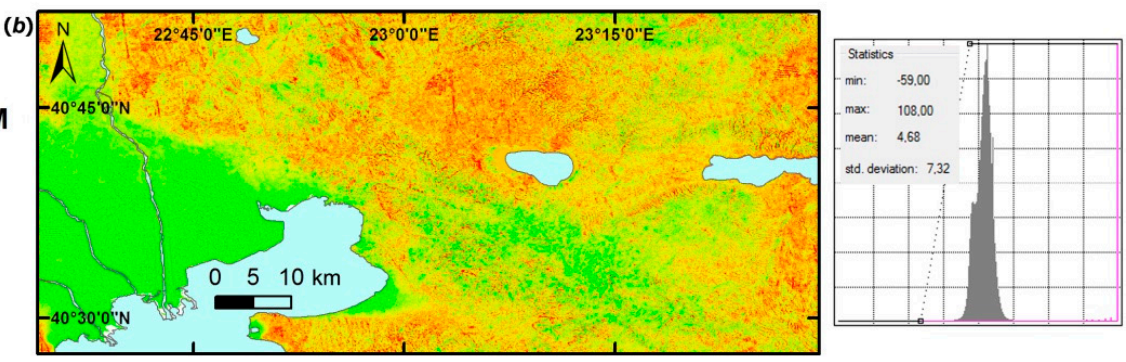

Legend

\section{Water body}

SRTM DEM-ASTER GDEM

Elevation difference $(m)$

Max: 120

Min: -65
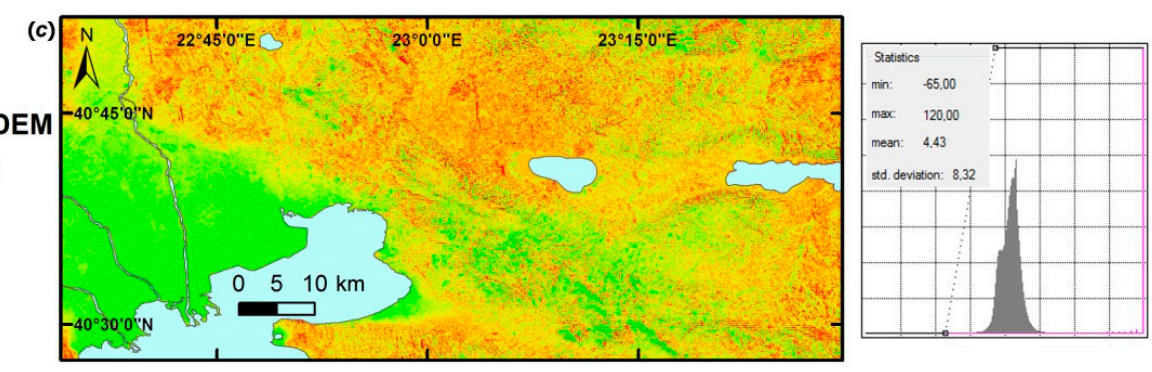

Figure 2. Elevation comparison by subtraction of corresponding pixel values, between the original version of EU-DEM (v1), SRTM DEM and ASTER GDEM in the area of interest: (a) (EU-DEM) - SRTM DEM, (b) (EU-DEM) - ASTER GDEM and (c) SRTM DEM - ASTER GDEM.
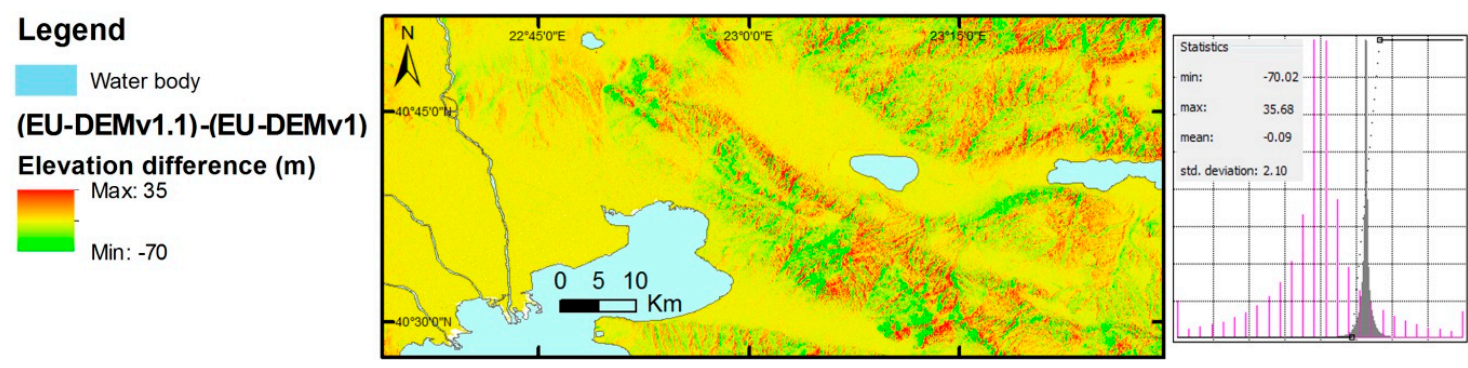

Figure 3. Elevation comparison by subtraction of corresponding pixel values, between the original version of EU-DEM (EU-DEMv1) and the upgraded version (EU-DEMv1.1) in the area of interest. 


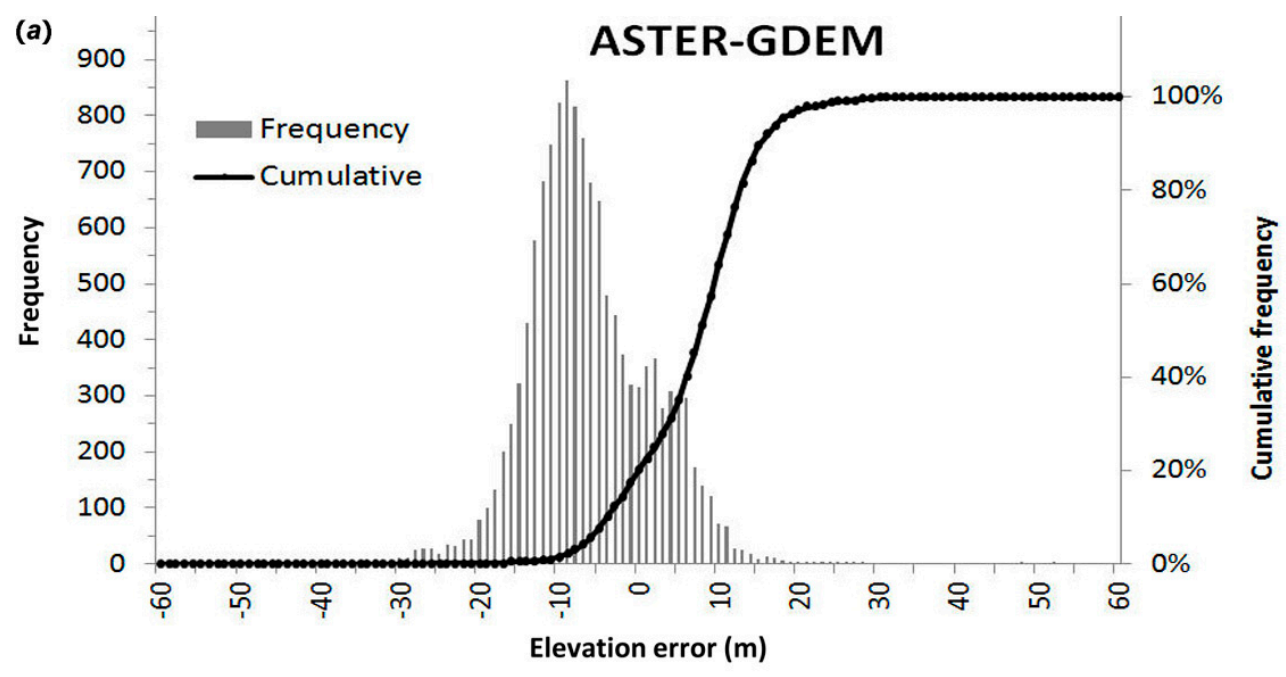

(b)
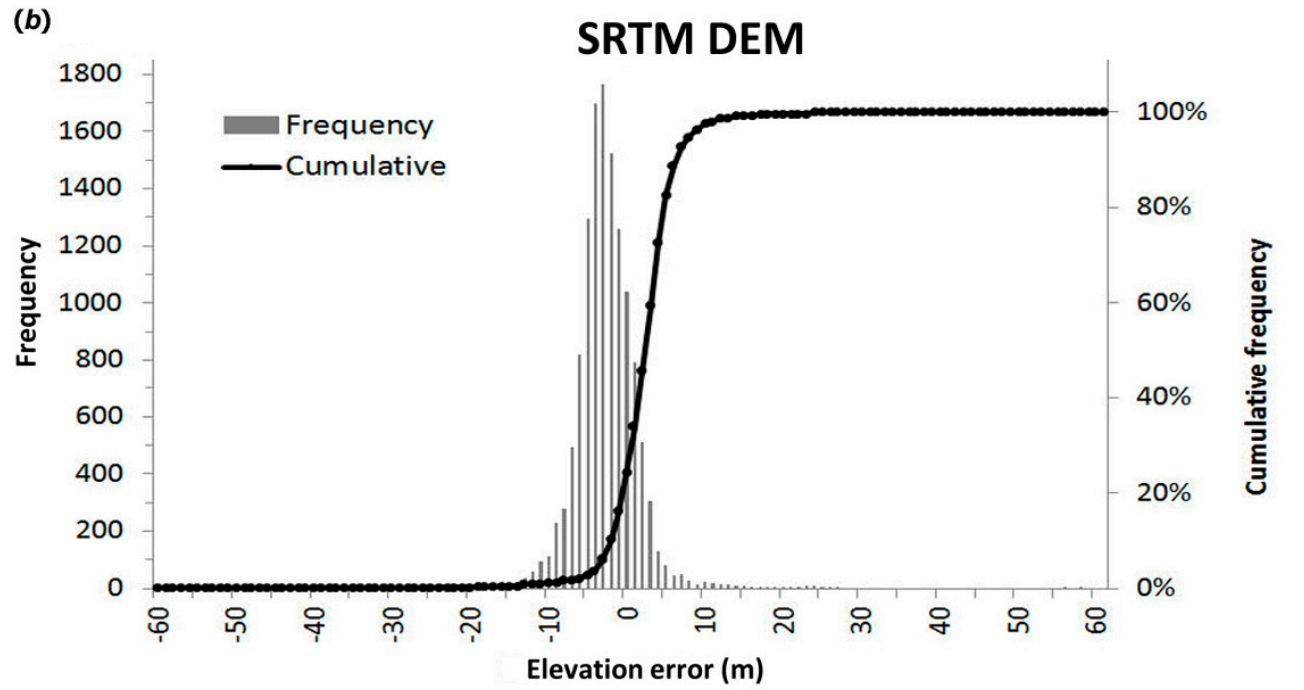

(c)

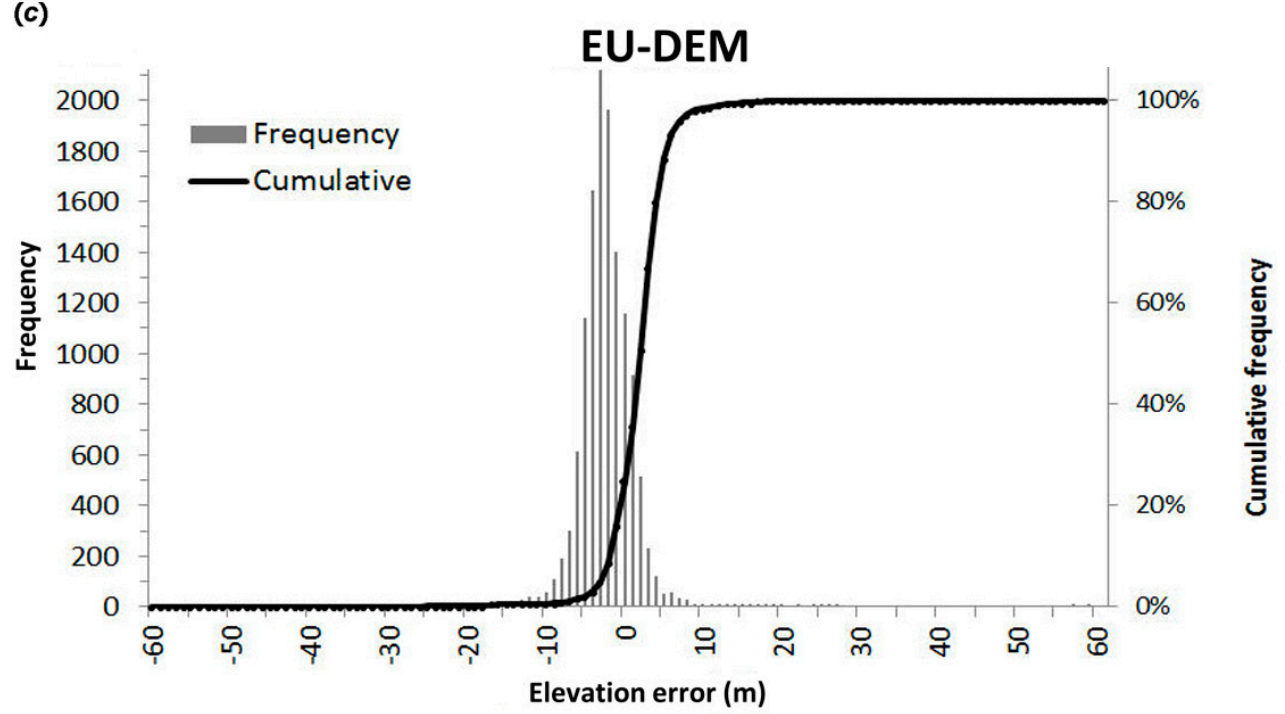

Figure 4. Histograms of absolute elevation errors for the three DEMs: (a) ASTER-GDEM, (b) SRTM DEM and (c) EU-DEM. 


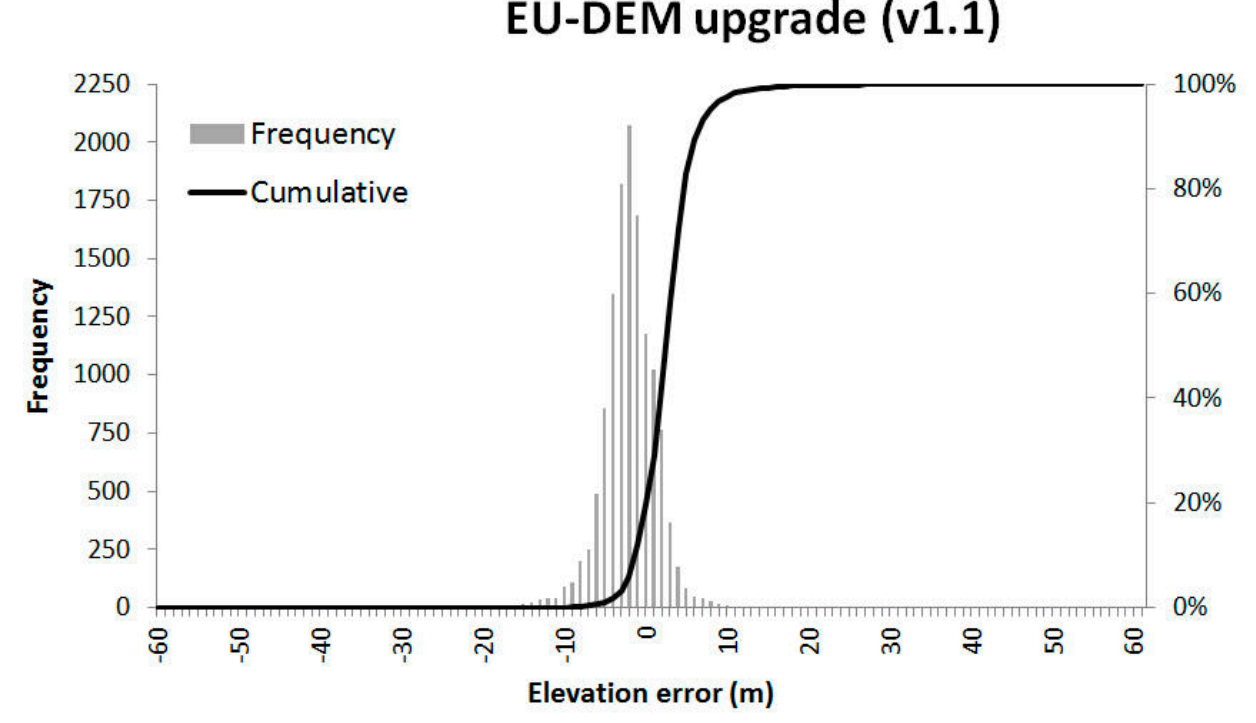

Figure 5. Histogram of absolute elevation errors for the EU-DEM upgrade (v1.1).

Table 1. Absolute elevation errors: descriptive and other statistics for the three evaluated DEMs. EU-DEM performs significantly better in most of the statistical parameters evaluated.

\begin{tabular}{ccccc}
\hline Statistical Measure & ASTER GDEM & SRTM DEM & EU-DEM & EU-DEM Upgrade (v1.1) \\
\hline Mean (m) & -6.8 & -2.2 & -1.8 & -2.6 \\
Standard Deviation (m) & 7.6 & 4.3 & 3.6 & 3.4 \\
RMSE (m) & 10.2 & 4.8 & 4.0 & 4.3 \\
RMSE 95\% (m) & 9.1 & 3.6 & 3.0 & 3.4 \\
RMSE 90\% (m) & 8.5 & 3.2 & 2.7 & 3.0 \\
Median (m) & -7.8 & -2.3 & -2.0 & -2.5 \\
Normalized Median Absolute & 6.8 & 3.0 & 2.6 & 2.7 \\
Deviation (NMAD) (m) & 0.8 & 17.4 & 21.7 & 7.7 \\
(Excess) Kurtosis & 0.3 & 0.4 & 1.3 & -1.2 \\
Skewness & 51.6 & 58.6 & 59.3 & 10.0 \\
Maximum (m) & -36.6 & -59.4 & -27.1 & -33.6 \\
Minimum (m) & 88.2 & 118 & 86.4 & 43.6 \\
Range (m) & 12,943 & 12,943 & 12,943 & 12,943 \\
\hline
\end{tabular}

Table 1 shows that the EU-DEM upgrade (v1.1) has succeeded in considerably reducing the outliers in v1 (reduction in kurtosis and range); however, it is overall somewhat less accurate than the original EU-DEM version.

\subsection{Relative Elevation}

To estimate the relative vertical accuracy, a random selection of 1000 GNSS points from the total of 12,943 took place. Relative accuracy was then calculated (Figures 6 and 7, Table 2) on the basis of almost 500,000 computed elevation differences, i.e., of all possible combinations between the selected points. The results indicate that, with respect to relative errors, EU-DEM is the most consistent dataset, but with SRTM DEM being very close in all statistics. ASTER GDEM has significantly larger error range and standard deviation values compared with the other two datasets (Table 2). 

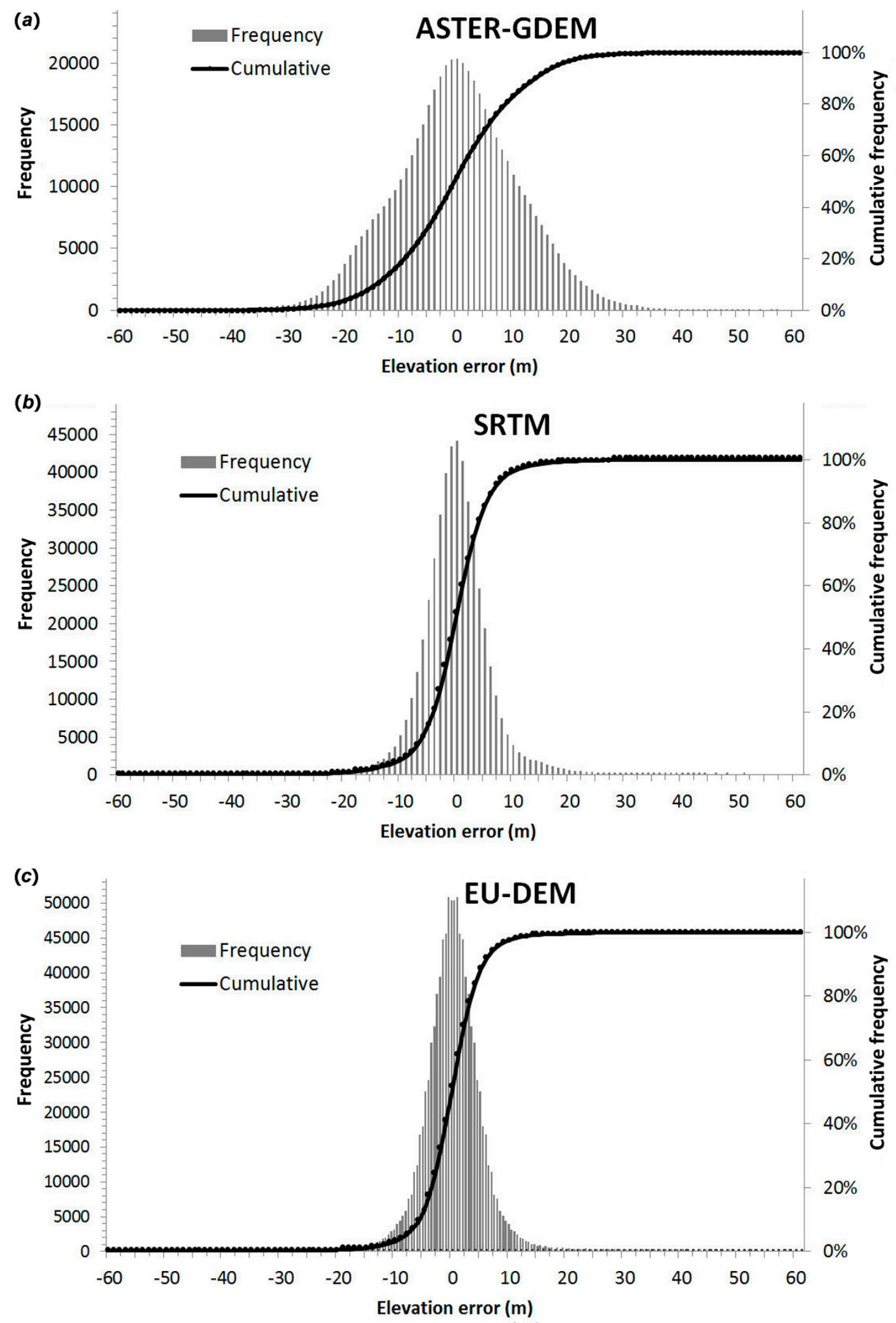

Figure 6. Histograms of relative elevation errors for the three DEMs: (a) ASTER-GDEM, (b) SRTM DEM, (c) EU-DEM. 


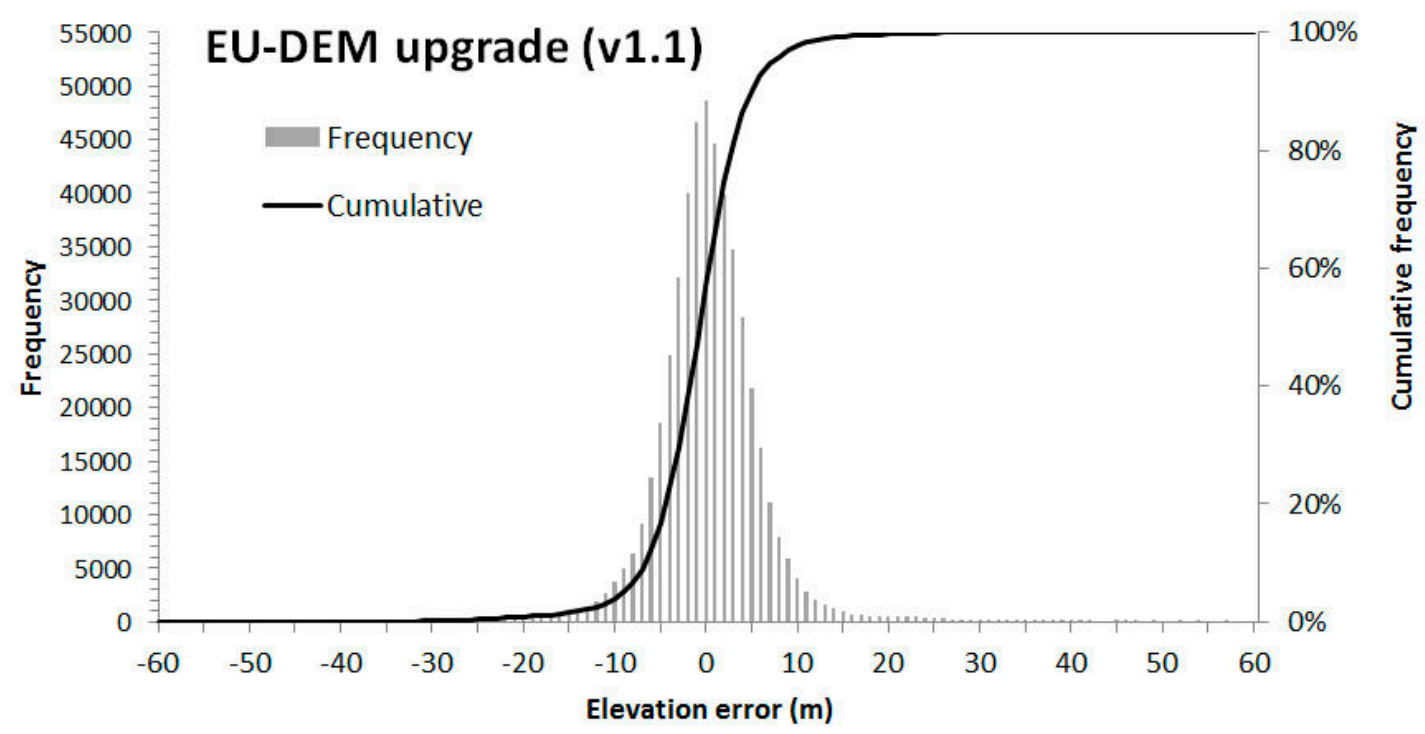

Figure 7. Histogram of relative elevation errors for the EU-DEM upgrade (v1.1).

Table 2. Relative elevation errors: descriptive and other statistics for the three DEMs under evaluation. EU-DEM performed considerably better in most of the statistical parameters evaluated.

\begin{tabular}{ccccc}
\hline Statistical Measure & ASTER GDEM & SRTM DEM & EU-DEM & EU-DEM Upgrade (v1.1) \\
\hline Mean (m) & 0.4 & 0.3 & 0.2 & 0.9 \\
Standard Deviation (m) & 11.0 & 6.1 & 5.3 & 5.5 \\
RMSE (m) & 11.0 & 6.1 & 5.3 & 5.6 \\
RMSE 95\% (m) & 9.5 & 4.6 & 3.9 & 3.1 \\
RMSE 90\% (m) & 8.6 & 4.0 & 3.4 & 0.7 \\
Median (m) & 0.4 & 0.2 & 0.1 & 4.2 \\
Normalized Median Absolute & 10.4 & 4.7 & 4.1 & 5.2 \\
Deviation (NMAD) (m) & 0.3 & 3.6 & 4.7 & 0.5 \\
(Excess) Kurtosis & 0.0 & 0.2 & 0.0 & 57.0 \\
Skewness & 57.8 & 51.1 & 48.1 & -38.7 \\
Maximum (m) & -54.6 & -50.0 & -51.4 & 95.7 \\
Minimum (m) & 112.4 & 101.1 & 99.5 & 499,500 \\
Range (m) & 499,500 & 499,500 & 499,500 & \\
n (number pixel differences & & & \\
\hline
\end{tabular}

\subsection{Slope}

Irrespective of the elevation at which it occurs, slope is a crucial factor that controls DEM vertical accuracy $[19,23,26,27,55]$. Efforts to decompose and model elevation differences on the basis of aspect and slope terrain classes, to overcome the systematic errors in datasets such as SRTM, have already been reported [56-58].

To investigate this aspect, slope was calculated from the most accurate and higher spatial resolution available dataset, i.e., from the original version of EU-DEM, which was subsequently plotted against elevation errors for all other DEMs, together with the modelled DEM errors presented by Becek [57] (Figure 8).

The results show the consistency of SRTM DEM and EU-DEM: elevation errors are small and increase gradually with slope, as expected. This primarily occurs over flat terrain up to slope values of about $12^{\circ}$, whereas EU-DEM continues to be very consistent up to $14^{\circ}$. ASTER GDEM does not exhibit this behavior; starting at considerably higher values, errors tend to decrease or remain at the same level up to slopes of $16^{\circ}$. The overall bias of ASTER GDEM is also evident through the comparison against the modeled errors for a $30 \mathrm{~m}$ DEM. 


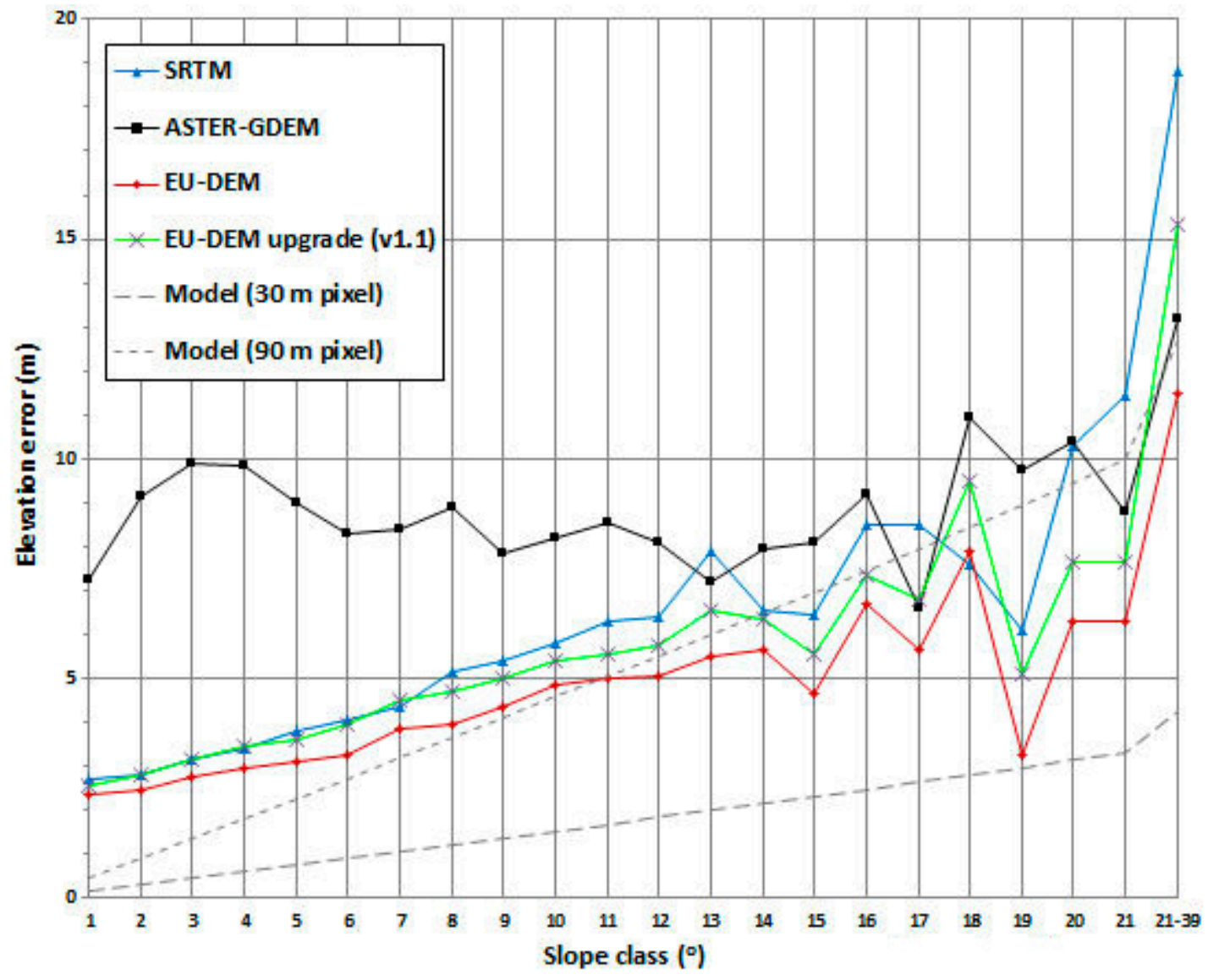

Figure 8. Absolute elevation errors plotted against slope variations for all DEMs. The modelled errors for DEMs with pixel size of $30 \mathrm{~m}$ and $90 \mathrm{~m}$ were adapted from Becek [57].

At higher slope values $\left(>13^{\circ}\right)$, owing to its higher spatial resolution, ASTER GDEM begins to exceed the accuracy of SRTM DEM in many cases. Progressively, for slope values greater than $20^{\circ}$, ASTER GDEM permanently exhibits higher accuracy than SRTM DEM. The same does not occur between ASTER GDEM and EU-DEM, as their elevation values generally remain equally reliable in steep slope areas.

The upgraded version (v1.1) of EU-DEM exhibits a rather constant (by about $0.5-1 \mathrm{~m}$ ) deteriorated accuracy with respect to the original EU-DEM version, as expected from the previous results of absolute elevation evaluation (Table 1). However, for maximum slope values $\left(21^{\circ}-39^{\circ}\right)$, the error of EU-DEM v1.1 increases by almost $5 \mathrm{~m}$ compared to the respective error of the original EU-DEM version.

Overall, the errors of the original version of EU-DEM are closer to the expected (modelled) errors for a $30 \mathrm{~m}$ DEM.

\subsection{Land Cover}

SRTM DEM, ASTER GDEM, and EU-DEM are Digital Surface Models (DSMs), so thus include the elevation of buildings, trees, and other objects, and do not necessarily refer to the ground surface. Consequently, depending on the type of land cover, the actual terrain elevation could be overestimated by DEMs, even if the measurement itself is accurate.

Therefore, as a last step, robust statistics, i.e., median (Figure 9, Table 3) and NMAD (Figure 10, Table 4) of the absolute elevation errors were used in order to evaluate the impact of different land cover classes on elevation accuracy. Corine Land Cover 2012 datasets were employed for this purpose. 


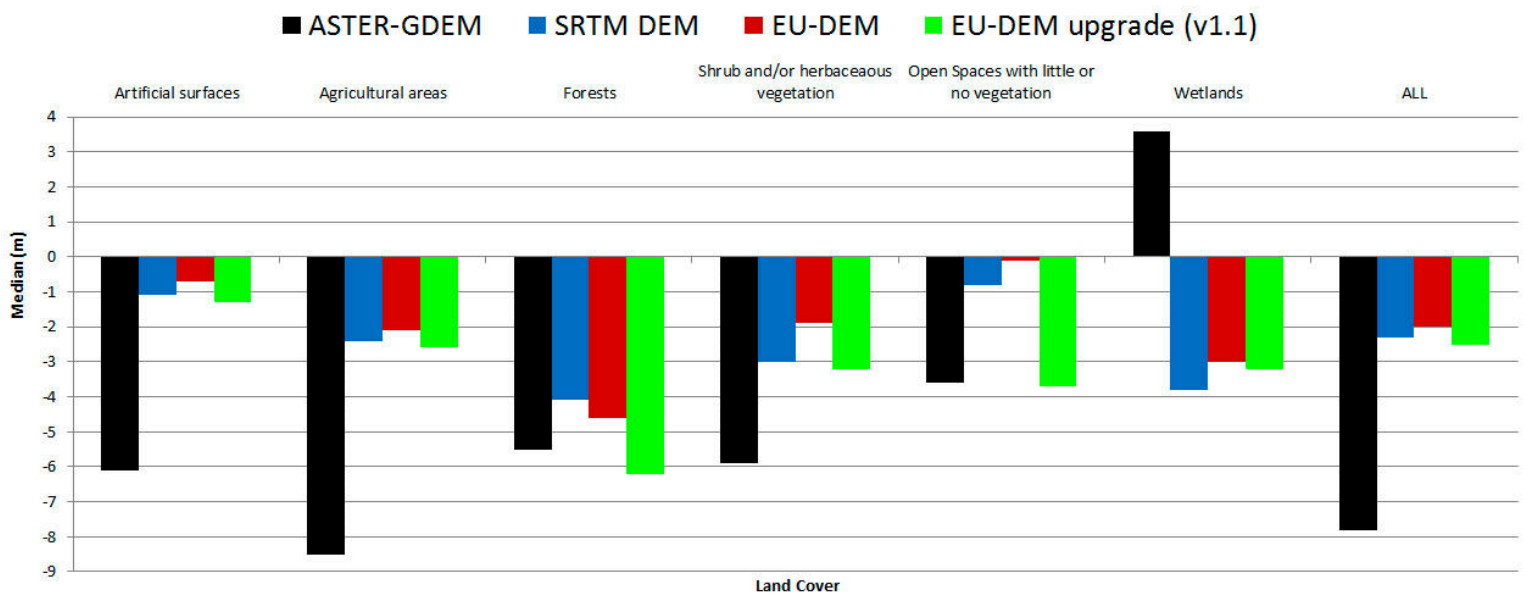

Figure 9. Median of absolute elevation errors plotted against different land cover classes.

Table 3. Median of absolute elevation error values per land cover.

\begin{tabular}{ccccc}
\hline \multirow{2}{*}{ Land Cover Type } & \multicolumn{3}{c}{ Median } \\
\cline { 2 - 5 } & ASTER-GDEM & SRTM DEM & EU-DEM & EU-DEM Upgrade (v1.1) \\
\hline Artificial surfaces & -6.1 & -1.1 & -0.7 & -1.3 \\
Agricultural areas & -8.5 & -2.4 & -2.1 & -2.6 \\
Forests & -5.5 & -4.1 & -4.6 & -6.2 \\
Shrub and or herbaceous vegetation & -5.9 & -3.0 & -1.9 & -3.2 \\
Open Spaces with little or no vegetation & -3.6 & -0.8 & -0.1 & -3.7 \\
Wetlands & 3.6 & -3.8 & -3.0 & -3.2 \\
ALL & -7.8 & -2.3 & -2.0 & -2.5 \\
\hline
\end{tabular}

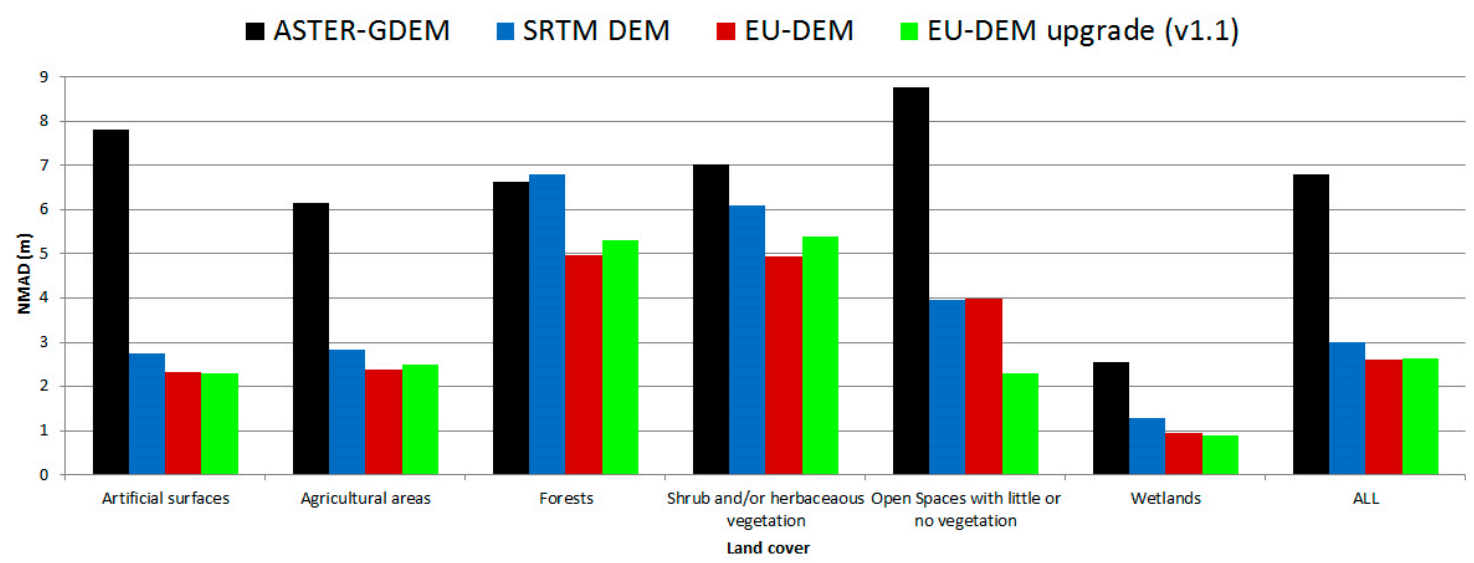

Figure 10. Normalized Median Absolute Deviation (NMAD) of absolute elevation errors plotted against different land cover classes.

Table 4. Normalized Median Absolute Deviation (NMAD) of absolute elevation error values per land cover.

\begin{tabular}{ccccc}
\hline \multirow{2}{*}{ Land Cover Type } & \multicolumn{3}{c}{ NMAD } \\
\cline { 2 - 5 } & ASTER-GDEM & SRTM DEM & EU-DEM & EU-DEM Upgrade (v1.1) \\
\hline Artificial surfaces & 7.8 & 2.7 & 2.3 & 2.3 \\
Agricultural areas & 6.1 & 2.8 & 2.4 & 2.5 \\
Forests & 6.6 & 6.8 & 5.0 & 5.3 \\
Shrub and /or herbaceous vegetation & 7.0 & 6.1 & 5.0 & 5.4 \\
Open Spaces with little or no vegetation & 8.8 & 4.0 & 4.0 & 2.3 \\
Wetlands & 2.6 & 1.3 & 1.0 & 0.9 \\
ALL & 6.8 & 3.0 & 2.6 & 2.6 \\
\hline
\end{tabular}


The results demonstrate that the elevation accuracy of the original version of EU-DEM is higher than in any other DEM for all land cover classes except for forests, where SRTM performs slightly better. The upgraded version of EU-DEM (v1.1) is consistently characterized by lower accuracy than the original version for all land cover classes, but is also of considerably lower accuracy when compared to SRTM data for almost all land cover classes (apart from wetlands). In forested areas as well as open spaces with little or no vegetation, EU-DEM v1.1. performs worse than ASTER-GDEM. The variability in errors in EU-DEM v1.1 was always considerably lower than both SRTM DEM and ASTER-GDEM and occasionally even lower than that of the original version of EU-DEM.

\section{Discussion}

The results of this study show that EU-DEM is a product with generally more similarities to SRTM DEM in terms of elevation values, but closer to ASTER GDEM for slopes greater than $20^{\circ}$. Thus, if restricted to a mountainous area, or steep slopes to be exact, EU-DEM would more approximate ASTER GDEM rather than SRTM data.

The RMSE of the absolute and relative vertical accuracy of EU-DEM were estimated at 4.0 and $5.3 \mathrm{~m}$, respectively, which are better than SRTM DEM ( $4.8 \mathrm{~m}$ and $6.1 \mathrm{~m}$, respectively) and ASTER GDEM (10.2 m and $11.0 \mathrm{~m}$, respectively). Additionally, more robust statistics (median and NMAD) indicate the consistently better performance of EU-DEM. The calculated accuracy applies to the specific area of interest and is thus of local value, but may diverge considerably in other areas depending on the type of terrain and slope. To this end, the whole original EU-DEM dataset (i.e., of regional or even continental value) performs better at both low and high elevations when compared with either SRTM DEM or ASTER GDEM. With respect to the findings of the previous evaluation of the original version of EU-DEM in Hungary [37], the RMSE values were found to be considerably lower (4.0 $\mathrm{m}$ in this study versus $6.0 \mathrm{~m}$ to $7.8 \mathrm{~m}$ in Józsa et al. [37]). When compared to the official validation results [10], the RMSE values (95\%) of this study are somewhat higher than those calculated for Greece (3.0 $\mathrm{m}$ in this study versus $2.0 \mathrm{~m}$ in the EU-DEM Statistical Validation Report [10]), but closer to the general accuracy of EU-DEM v1 south of $60^{\circ}(3.0 \mathrm{~m}$ in this study versus $2.2 \mathrm{~m}$ in the EU-DEM Statistical Validation Report [10]) and very close to the overall EU-DEM v1 vertical accuracy (3.0 $\mathrm{m}$ in this study versus 2.9 $m$ in the EU-DEM Statistical Validation Report [10]).

Concerning the validation of elevation accuracy against different types of land cover, forests present the most problematic areas in all DEMs, with the exception of ASTER-GDEM. ASTER-GDEM has considerably lower accuracy over agricultural areas, which can be linked to its low accuracy over relatively flat terrain (where most agricultural activity is performed).

The EU-DEM upgrade (v1.1) reduces the overall variability in the elevation errors and suppresses outliers. However, this has been accompanied by some loss of elevation accuracy with respect to the original EU-DEM, as indicated by their respective RMSEs of $3.4 \mathrm{~m}$ and $3.0 \mathrm{~m}$ at $95 \%$ confidence. Therefore, as both versions are the result of the implementation of mathematical formulas and do not represent original measurements, they ought to be handled with extra care, especially when the existence of artefacts may have a severe impact (e.g., in hydrological modelling or geomorphological investigations).

\section{Conclusions}

In conclusion, EU-DEM is an advancement regarding its combination of spatial resolution and vertical accuracy, achieved by maintaining the higher resolution of ASTER GDEM and the vertical accuracy of both SRTM DEM and ASTER GDEM in low and high slope areas, respectively. While benefiting from the 1 arcsecond spatial resolution of ASTER GDEM, EU-DEM generally follows the consistency of SRTM DEM for relatively low slope values, whereas it exhibits the accuracy of ASTER GDEM in steep terrain. Generally, regarding vertical accuracy and spatial resolution, EU-DEM is an enhanced product, benefiting from both SRTM DEM and ASTER GDEM datasets and meeting the objectives of its implementation. 
Overall, owing to the ever growing need for an accurate description of the global topography and its changes, the production of modern and (almost) global or regional DEMs is becoming more frequent, in the form of either primary or secondary products. As these new elevation datasets are typically becoming more accurate, the validation procedure is also becoming more demanding in terms of availability, volume, sampling, and accuracy of reliable reference topographic information. Such information can be relatively easily retrieved with the use of kinematic GNSS surveys, using dual frequency receivers with hundreds of channels and taking advantage of the GNSS constellations currently available (GPS, GLONASS, GALILEO, and BEIDOU).

As a consequence, part of future research on DEM validation should focus both on the accuracy assessment of more DEMs as they are being made available to the scientific community, but also on providing appropriate reference datasets for assessing the reliability and limitations of new and popular topographic products.

Author Contributions: Conceptualization, A.M.; Data curation, A.M. and D.A.; Methodology, A.M. and D.A.; Visualization, A.M.; Writing—original draft, A.M.; Writing—review \& editing, A.M. and D.A.

Funding: This research received no external funding.

Acknowledgments: The European Union Digital Elevation Model was downloaded and adapted as produced using Copernicus data and information funded by the European Union EU-DEM layers, with no modifications. ASTER GDEM is a product and property of METI (Ministry of Economy, Trade and Industry of Japan) and NASA. Colleagues at the European Environment Agency (EEA) are gratefully acknowledged for providing details, as well as related documents concerning the production and statistical validation of EU-DEM. Last but not least, the authors would also like to thank the anonymous referees, for significantly improving the final form of this article with their constructive comments and suggestions.

Conflicts of Interest: The authors declare no conflict of interest.

\section{References}

1. Farr, T.G.; Kobrick, M. Shuttle radar topography mission produces a wealth of data. Eos 2000, 81, 583-585. [CrossRef]

2. Meyer, D.; Tachikawa, T.; Kaku, M.; Iwasaki, A.; Gesch, D.; Oimoen, M.; Zhang, Z.; Danielson, J.; Krieger, T.; Curtis, B.; et al. Summary for Policymakers. In Climate Change 2013-The Physical Science Basis; Intergovernmental Panel on Climate Change, Ed.; Cambridge University Press: Cambridge, UK, 2011; pp. 1-30. ISBN 9788578110796.

3. ASTER Global DEM Validation Summary Report. Available online: https://lpdaac.usgs.gov/sites/default/ files/public/aster/docs/ASTER_GDEM_Validation_Summary_Report.pdf (accessed on 4 January 2014).

4. Tachikawa, T.; Hato, M.; Kaku, M.; Iwasaki, A. Characteristics of ASTER GDEM version 2. In Proceedings of the International Geoscience and Remote Sensing Symposium (IGARSS), Vancouver, BC, Canada, 24-29 July 2011; pp. 3657-3660.

5. Massonnet, D.; Elachi, C. High-resolution land topography. C. R. Geosci. 2006, 338, 1029-1041. [CrossRef]

6. ALOS Global Digital Surface Model "ALOS World 3D-30m (AW3D30)". Available online: https://www. eorc.jaxa.jp/ALOS/en/aw3d30/index.htm (accessed on 24 January 2019).

7. Airbus-Elevation Models. Available online: http://www.astrium-geo.com/worlddem (accessed on 30 December 2018).

8. Lidar Surface Topography (LIST). Available online: https://eospso.nasa.gov/missions/lidar-surfacetopography (accessed on 24 January 2019).

9. EU-DEM. Available online: http://www.eea.europa.eu/data-and-maps/data/eu-dem (accessed on 3 January 2015).

10. EU-DEM Statistical Validation Report. Available online: http://land.copernicus.eu/user-corner/technicallibrary (accessed on 5 May 2015).

11. EU-DEM v1.1. Available online: https://land.copernicus.eu/imagery-in-situ/eu-dem/eu-dem-v1.1?tab= metadata (accessed on 30 December 2018).

12. Denker, H. Evaluation of SRTM3 and GTOPO30 Terrain Data in Germany. Gravity Geoid Space Mission. 2005, 129, 218-223. [CrossRef] 
13. Hirt, C.; Filmer, M.S.; Featherstone, W.E. Comparison and validation of the recent freely available ASTER-GDEM ver1, SRTM ver4.1 and GEODATA DEM-9s ver3 digital elevation models over Australia. Aust. J. Earth Sci. 2010, 57, 337-347. [CrossRef]

14. Paul, D.; Mandla, V.R.; Singh, T. Quantifying and modeling of stream network using digital elevation models. Ain Shams Eng. J. 2017, 8, 311-321. [CrossRef]

15. Rodríguez, E.; Morris, C.S.; Belz, J.E. A Global Assessment of the SRTM Performance. Photogramm. Eng. Remote Sens. 2006, 72, 249-260. [CrossRef]

16. Tachikawa, T.; Kaku, M.; Iwasaki, A. ASTER GDEM Version 2 Validation Report. In Proceedings of the International Geoscience and Remote Sensing Symposium, Vancouver, BC, Canada, 24-29 July 2011; pp. 1-24.

17. Foumelis, M.; Chalkias, C.; Plank, S. Influence of Satellite Imaging Geometry on ASTER and SRTM Global Digital Elevation Models. In Proceedings of the 10th International Congress of the Hellenic Geographical Society, Thessaloniki, Greece, 22-24 October 2014; Mouratidis, A., Ed.; Hellenic Geographical Society: Thessaloniki, Greece, 2014; pp. 275-286.

18. Miliaresis, G.C.; Paraschou, C.V.E. An evaluation of the accuracy of the ASTER GDEM and the role of stack number: A case study of Nisiros Island, Greece. Remote Sens. Lett. 2011, 2, 127-135. [CrossRef]

19. Miliaresis, G.C.; Paraschou, C.V.E. Vertical accuracy of the SRTM DTED level 1 of Crete. Int. J. Appl. Earth Obs. Geoinf. 2005, 7, 49-59. [CrossRef]

20. Weydahl, D.J.; Sagstuen, J.; Dick, B.; Rønning, H. SRTM DEM accuracy assessment over vegetated areas in Norway. Int. J. Remote Sens. 2007, 28, 3513-3527. [CrossRef]

21. Helm, A.; Braun, A.; Eickschen, S.; Schöne, T. Calibration of the shuttle radar topography mission X-SAR instrument using a synthetic altimetry data model. Can. J. Remote Sens. 2002, 28, 573-580. [CrossRef]

22. Sun, G.; Ranson, K.J.; Kharuk, V.I.; Kovacs, K. Validation of surface height from shuttle radar topography mission using shuttle laser altimeter. Remote Sens. Environ. 2003, 88, 401-411. [CrossRef]

23. Gorokhovich, Y.; Voustianiouk, A. Accuracy assessment of the processed SRTM-based elevation data by CGIAR using field data from USA and Thailand and its relation to the terrain characteristics. Remote Sens. Environ. 2006, 104, 409-415. [CrossRef]

24. Bulatović, V.; Sušić, Z.; Ninkov, T. Estimate of the ASTER GDEM regional systematic errors and their removal. Int. J. Remote Sens. 2012, 33, 5915-5926. [CrossRef]

25. Li, P.; Shi, C.; Li, Z.; Muller, J.P.; Drummond, J.; Li, X.; Li, T.; Li, Y.; Liu, J. Evaluation of ASTER GDEM using GPS benchmarks and SRTM in China. Int. J. Remote Sens. 2013, 34, 1744-1771. [CrossRef]

26. Mouratidis, A.; Briole, P.; Katsambalos, K. SRTM 3" DEM (versions 1, 2, 3, 4) validation by means of extensive kinematic GPS measurements: A case study from North Greece. Int. J. Remote Sens. 2010, 31, 6205-6222. [CrossRef]

27. Rodriguez, E.; Morris, C.S.; Belz, J.E.; Chapin, E.C.; Martin, J.M.; Daffer, W.; Hensley, S. An Assessment of the SRTM Topographic Products; Technical Report JPL D-31639; JPL, NASA: Pasadena, CA, USA, 2005.

28. Werner, M. Shuttle Radar Topography Mission (SRTM) mission overview. Frequenz 2001, 55, 75-79. [CrossRef]

29. Rabus, B.; Eineder, M.; Roth, A.; Bamler, R. The shuttle radar topography mission-A new class of digital elevation models acquired by spaceborne radar. ISPRS J. Photogramm. Remote Sens. 2003, 57, 241-262. [CrossRef]

30. Farr, T.G.; Rosen, P.A.; Caro, E.; Crippen, R.; Duren, R.; Hensley, S.; Kobrick, M.; Paller, M.; Rodriguez, E.; Roth, L.; et al. The shuttle radar topography mission. Rev. Geophys. 2007, 45, RG2004. [CrossRef]

31. Mukul, M.; Srivastava, V.; Jade, S.; Mukul, M. Uncertainties in the Shuttle Radar Topography Mission (SRTM) Heights: Insights from the Indian Himalaya and Peninsula. Sci. Rep. 2017, 7, 41672. [CrossRef] [PubMed]

32. ASTER Global Digital Elevation Model Version 2-Summary of Validation Results. Available online: https://ssl.jspacesystems.or.jp/ersdac/GDEM/ver2Validation/Summary_GDEM2_validation_ report_final.pdf (accessed on 2 February 2019).

33. Varga, M.; Bašić, T. Accuracy validation and comparison of global digital elevation models over Croatia. Int. J. Remote Sens. 2015, 36, 170-189. [CrossRef]

34. Mouratidis, A. Contribution of - GPS and GIS-Assisted Spaceborne Remote Sensing in the Morphotectonic Research of Central Macedonia (Northern Greece); Aristotle University of Thessaloniki: Thessaloniki, Greece, 2010.

35. Copernicus Land Monitoring Service-Reference Data: EU-DEM. Available online: https://land.copernicus. eu/user-corner/publications/eu-dem-flyer/view (accessed on 2 January 2019).

36. EU-DEM Upgrade Documentation EEA User Manual. Available online: https://land.copernicus.eu/usercorner/technical-library / eu-dem-v1-1-user-guide (accessed on 2 January 2019). 
37. Józsa, E.; Fábián, S.Á.; Kovács, M. An evaluation of EU-DEM in comparison with ASTER GDEM, SRTM and contour-based DEMs over the Eastern Mecsek Mountains. Hung. Geogr. Bull. 2014, 63, 401-423. [CrossRef]

38. Jarvis, A.; Reuter, H.I.; Nelson, A.; Guevara, E. Hole-Filled SRTM for the Globe Version 4, available from the CGIAR-CSI SRTM 90m Database. Available online: http:/ / srtm.csi.cgiar.org (accessed on 4 January 2019).

39. Lemoine, F.G.; Kenyon, S.C.; Factor, J.K.; Trimmer, R.G.; Pavlis, N.K.; Chinn, D.S.; Cox, C.M.; Klosko, S.M.; Luthcke, S.B.; Torrence, M.H.; et al. The NASA GSFC and NIMA Joint Geopotential Model. Available online: https:/ / ntrs.nasa.gov/archive/nasa/casi.ntrs.nasa.gov/19980218814.pdf (accessed on 4 January 2019).

40. Mouratidis, A.; Albanakis, K. Hypsometric changes near Kavallari based on multi-temporal DEMs and extensive GNSS measurements. In Proceedings of the 9th Geographical Conference of Greece, Athens, Greece, 4-6 November 2010; pp. 116-123.

41. Altamimi, Z.; Collilieux, X.; Legrand, J.; Garayt, B.; Boucher, C. ITRF2005: A new release of the International Terrestrial Reference Frame based on time series of station positions and Earth Orientation Parameters. J. Geophys. Res. Solid Earth 2007, 112. [CrossRef]

42. CORINE Land Cover/CLC 2012. Available online: https:/ /land.copernicus.eu/pan-european/corine-landcover/clc-2012?tab=download (accessed on 4 January 2019).

43. ITRS and WGS84. Available online: ftp://itrf.ensg.ign.fr/pub/itrf/WGS84.TXT (accessed on 4 January 2019).

44. Boucher, C.; Altamimi, Z. Specifications for Reference Frame Fixing in the Analysis of a EU-REF GPS Campaign. Available online: http:/ / etrs89.ensg.ign.fr/memo-V7.pdf (accessed on 4 January 2019).

45. Augath, W.; Ihde, J. EUREF Permanent GNSS Network-ETRF/ITRF Transformation. Available online: http:/ / www.epncb.oma.be/_productsservices/coord_trans/index.php (accessed on 4 January 2019).

46. Gruber, T. Evaluation of the EGM08 Gravity Field by Means of GPS-Levelling and Sea Surface Topography Solutions. Available online: https:/ / mediatum.ub.tum.de/doc/1368753/file.pdf (accessed on 28 February 2019).

47. Kotsakis, C.; Katsambalos, K. Quality Analysis of Global Geopotential Models at 1542 GPS/levelling Benchmarks over the Hellenic Mainland. Surv. Rev. 2010, 42, 327-344. [CrossRef]

48. Rizos, C.; Grejner-Brzezinska, D. Geodesy and Surveying. In GNSS Applications and Methods; Gleason, S., Gebre-Egziabher, D., Eds.; Artech House: Boston, MA, USA, 2009; pp. 347-380. ISBN 9781596933293.

49. Weikko, A.H.; Moritz, H. Physical Geodesy; W. H. Freeman and Company: San Francisco, CA, USA, 1967.

50. EGM2008-WGS 84 Version. Available online: Earth-info.nga.mil/GandG/wgs84/gravitymod/egm2008/ egm08_wgs84.html (accessed on 4 January 2019).

51. Kotsakis, C.; Katsambalos, K.; Ampatzidis, D.; Gianniou, M. Evaluation of EGM08 Using GPS and Leveling Heights in Greece. In International Association of Geodesy Symposia; Springer: Cham, Switzerland, 2010; Volume 135, pp. 481-488.

52. Pavlis, N.K.; Holmes, S.A.; Kenyon, S.C.; Factor, J.K. The development and evaluation of the Earth Gravitational Model 2008 (EGM2008). J. Geophys. Res. 2012, 117, B04406. [CrossRef]

53. Vergos, G.S.; Grigoriadis, V.N.; Tziavos, I.N.; Kotsakis, C. Evaluation of GOCE/GRACE Global Geopotential Models over Greece with Collocated GPS/Levelling Observations and Local Gravity Data. In Gravity, Geoid and Height Systems; Marti, U., Ed.; Springer: Cham, Switzerland, 2014; pp. 85-92.

54. Höhle, J.; Höhle, M. Accuracy assessment of digital elevation models by means of robust statistical methods. ISPRS J. Photogramm. Remote Sens. 2009, 64, 398-406. [CrossRef]

55. Frey, H.; Paul, F. On the suitability of the SRTM DEM and ASTER GDEM for the compilation of: Topographic parameters in glacier inventories. Int. J. Appl. Earth Obs. Geoinf. 2012, 18, 480-490. [CrossRef]

56. Miliaresis, G.C. The landcover impact on the aspect/slope accuracy dependence of the SRTM-1 elevation data for the humboldt range. Sensors 2008, 8, 3134-3149. [CrossRef] [PubMed]

57. Becek, K. Investigating error structure of shuttle radar topography mission elevation data product. Geophys. Res. Lett. 2008, 35. [CrossRef]

58. Becek, K. Assessing global digital elevation models using the runway method: The advanced spaceborne thermal emission and reflection radiometer versus the shuttle radar topography mission case. IEEE Trans. Geosci. Remote Sens. 2014, 52, 4823-4831. [CrossRef]

(C) 2019 by the authors. Licensee MDPI, Basel, Switzerland. This article is an open access article distributed under the terms and conditions of the Creative Commons Attribution (CC BY) license (http:/ / creativecommons.org/licenses/by/4.0/). 